\title{
Awareness of Mental Health Challenges and its Implications for Job Performance among Library Staff at the Workplace: A Qualitative Study
}

\author{
Valeria Kyumana \\ Institute of Finance Management (IFM) \\ Email: asumptavaleria@yahoo.com
}

\begin{abstract}
Mental health is one of the neglected aspects at the workplace during planning and policy formulation that, in turn, affects job performance. This study, aimed to investigate awareness of mental health challenges among library staff at the Institute of Finance Management (IFM), Tanzania and their implications for job performance. Using a pragmatic qualitative research approach, the study conducted four FGDs coupled with interviews to collect data from library staff and heads of department and the head of the library. The resultant data was subjected to content relational analysis and findings were organised thematically. Findings revealed that most of the library staff had low awareness of mental health challenges such as depression, anxiety, stress and addictive behaviours but were familiar with symptoms such as extreme sadness, lack of will to do anything and constant fear. Stigma, lack of education and professional counsellors at the workplace and lack of management support emerged as major hindrances to maintaining a positive mental health. Availability of counsellors to help staff deal with life's challenges and navigate through personal problems; provision of education to reduce social stigma and honest conversations regarding mental health challenges were recommended as prerequisite for better mental health of library staff.
\end{abstract}

Keywords: Librarians mental health, library staff wellbeing, job performance, staff counselling, Tanzania, https://dx.doi.org/10.4314/udslj.v16i2.7

\section{Introduction}

In Africa, and Tanzania in particular, mental health has been neglected in health policy agendas and development strategies. At the national level, more focus is on the reduction of poverty, infectious diseases, maternal and child mortality rates while overlooking the agency of incorporating mental health amongst its people to enhance productivity and development (Jenkins et al., 2010; Japhet, 2018). In many cases, ignorance on the extent of mental health challenges, social stigma surrounding mental illnesses and traditional beliefs result in the persistence of the problem, hence finally culminating in devastating effects on individuals, family, organisations and the society at large (Bever, 2000; Barnett, 2010). 
Rothfuss (2007) in his classic book The Name of the Wind focuses on pain and its impact on people, noting that the greatest faculty people's minds possess is the ability to cope with pain. Yet, the mind when attacked travels through four doors, which include sleep, forgetting, madness and death. For madness (the third stage), the author elaborates that when the mind is dealt a fatal blow, it hides itself in insanity; for there are times when reality is reduced to pain, and to escape that pain the mind must leave reality behind.

Symptomatically, mental health challenges lead to workers having low or no energy, as they tend to feel numb, and experience unexplained aches, hopelessness and helplessness. In reaction, they tend to indulge in excessive smoking, drinking, or abuse of drugs. Sometimes they hear voices or believe things that are not true in addition to persistent thoughts and memories that are inexplicable and even suicidal thoughts. To make sense of these symptoms in an intelligent, smart and a good, hardworking person, many people individually and collectively heap blames it all on superstition and witchcraft (Erinosho, 1977; Bever, 2000; Barnett, 2012). Additionally, in social science field globally, researchers have studied and established links between mental health and social factors such as poverty, income inequalities and deprivation (Huxley, 2009). Yet, in many African countries, mental health challenges remain invisible despite their effects being devastating (Gberie, 2016).

Furthermore, Lund (2018) notes that unattended mental health challenges have negative effects on physical health, for instance, maternal depression affects the development and growth of infants. Meanwhile, conditions such as schizophrenia, bipolar mood disorder and depression lead to earlier death and expose one to non-communicable diseases as well as infectious diseases such as HIV/AIDS and TB due to substance abuse. Coincidentally, poverty in many Sub-Saharan Africa results in common mental health challenges namely depression and anxiety as poverty fuels stress on financial matters, food insecurity and income inadequacy, thus resulting in increased trauma and illness. In the meantime, lack of resources to cushion off the blow of these events aggravates mental health problems.

This dire situation necessitates mental health interventions aimed to improve the circumstances of people affected by mental health challenges. Yet, mental health challenges awareness amongst workers remain largely unexplored as many believe it would never happen to them (Chopra, 2009; Gberie, 2016; Evans, Holkar \& Murray, 2017). Crucially, ways to mitigate these challenges and offer help to workers challenged by mental health in many institutions remains largely non-existent. According to the World Health Organisation (WHO), the global economy loses about US \$ 1 trillion per annum in productivity due to depression and anxiety. It is against this backdrop that understanding the level of awareness of mental health challenges in the workplace and how it affects job performance is so crucial so that difficult conversations can be heard and solutions found, to bring those challenged back to normalcy and improve job performance; for no mind will ever exist without a touch of madness at one point in its life.

\section{Literature Review}

\section{Mental Health Awareness}

Mental health problems contribute more to the global burden of disease than most other disorders (Huxley, 2009). Although mental health falls more appropriately into the field of medicine

Awareness of Mental Health Challenges and its Implications for Job Performance among Library Staff at the Workplace: A Qualitative Study

Valeria Kyumana 
(Kamin, 2006), there has been a relationship between discourses of mental health and the social sciences (Huxley, 2009). Statistically, WHO reports that mental, neurological and substance use disorders account for 10 percent of the global burden of disease and 30 percent of non-fatal disease burden, adding that 1 in 5 of the world's children and adolescents have a mental disorder. Depression is one of the leading causes of disability, which affects 264 million people and about half of mental disorders begin before the age of 14. Additionally, almost 800,000 people die by suicide every year and that people with severe mental disorders die 10-20 years earlier than the general population (WHO, 2019).

In an article in Stanford Medicine, Zhang (2019) shares his experience of working in a psychiatric word and observed that everyone admitted was not outwardly ill; yet the admitted had schizophrenia, bipolar disorders and there were those who were catatonic. On the other hand, awareness made other people voluntarily get admitted to the hospital because they knew they were in trouble. However, in public- on the street or in the office they would seem like any other happy stranger when they were close to committing suicide or breaking point. Zhang (2019)'s experience shows the invisibility of mental health disorders. Thus, it is only by observing changed behaviour and symptoms that one can tell the other is in trouble.

Furthermore, mental health disorders are common in all countries of the world and largely affect socio-economic development and growth (Ambikile \& Iseselo, 2017). In developed countries, there is a growing movement for recognising the benefits of an all-inclusive approach to promoting mental health and wellbeing (Bywaters, 2005). Such efforts notwithstanding, these countries still face challenges of awareness, poor mental health literacy programmes and services for the mentally-challenged remain a vexing problem in many countries (Kamin, 2006). Meanwhile WHO reports that in low-income countries, rates of mental health workers vary from below 2 per 100,000 populations.

In the United Kingdom, Corlett (2012) reviewed the mental health policy and implementation framework and noted that there was, indeed, no health or development without mental health. Thus, the policy made commitment on parity between physical and mental health prevention, promotion and provision of access to talking therapy and tackling stigma. The gist of the policy is in the recognition that mental health is everyone's business.

In Africa, an exploration on mental health research led Sankoh, Sevalie and Weston (2018) to note that only twenty-one articles touched on depression, seven (7) on anxiety, six (6) on Suicide, four (4) on addiction, one (1) on psychosis and none on schizophrenia. In general, a search for "mental health disorders" in Africa produced sixteen (16) items, signalling the paucity of research on mental health problems in the region indicating that even the coverage of professional challenges in the workplace such as librarians is minimal.

In an article on mental illness invisibility yet with devastating consequences, Gberie (2016) narrates how and when an American film actor Robin Williams, who suffered from depression and committed suicide on August 11, 2014, one Kenyan writer wrote:

I can't wrap my mind around the fact that depression is an illness...in fact, it is such a non-issue that African languages never bothered to create a word for it.

The article appeared in The Standard newspaper carrying a headline "How Depression has Never Been an African Disease," thus capturing the general attitude held by many African 
people - both educated and non-educated - towards an epidemic of mental illness on the continent.

In Tanzania, Japhet (2018) proffers that mental health remains a taboo subject for much of the country's population, and the exact number of people with mental illness is hard to determine. Nevertheless, estimations put the number of people with mental illness in the country at about 500,000 individuals. Yet, only 118,730 patients with neuropsychiatric disorders and non-communicable diseases attended primary care facilities in 2007, according to a 10-year collaborative project (1999-2009) aimed to determine the impact of mental health (WHO, 2019).

Additionally, Kaaya (2014) notes that mental health concern in Tanzania needs to be addressed as many disorders do start in young adulthood. Thus, survival to adolescence is expected to increase the number of persons with mental disorders, ultimately leading to implications for lost productivity of patients and family while seeking traditional healing and other remedies. Moreover, mental health can impact on many aspects of people's lives including social relationships, health, productivity, and access to necessities. Furthermore, individuals may differ in their mental health and resilience thereafter due to their genetic traits and personality, as well as demographic factors such as socio-economic status, race, gender identity, and sexual orientation (Lanese, 2019; Parashar, 2019).

\section{Implications of Mental Health on Job Performance}

In an article titled 'Being 'difficult' or suffering from mental health issue?" Parashar (2019) exemplifies mental illness thusly:

My employee is lazy, he/she is unable to finish even the [...] simplest tasks assigned to him or her...My employee is constantly worrying and complaining about everything...he/she should learn to manage her worries...my employee is unable to manage his work stress, he/she starts drinking very early or even on the job non-stop.

The author notes that many employers have similar complaints about their employees at the workplace; many managers feel frustrated and angry with a certain worker and think it to be the person is difficult, lazy or has negative behaviour. Despite all the warnings and intervention, the worker does not seem to snap out of it and perform routine activities or assigned duties as work. In addition, Aultman (2016) identified the following symptoms in a student who reported a case of depression:

The patient reports that she has been experiencing very low moods, crying spells, and a profound lack of energy and motivation, making it difficult to do even the most basic activities in her life. Moreover, the lack of motivation and problems with concentration has made it very difficult to keep up with her work, and she expresses the concern that she might fail out of school.

These debilitating behaviours and symptoms could result from some mental health problem although many of the people believe that mental disorders may not happen to them (Parashar, 2019). Meanwhile, in Africa many believe one needs to eat from garbage bins and trash or walk

Awareness of Mental Health Challenges and its Implications for Job Performance among Library Staff at the Workplace: A Qualitative Study

Valeria Kyumana 
in the street naked and wear dirty as well as tattered clothes to be labelled mentally-ill. However, people varyingly experience feelings of sadness, anxiety, worry, irritability or sleep problems and substance use, which are common for most employees in their lives. Yet, when these feelings get very intense and last for a long time and result in poor work performance, absenteeism, lack of accountability at work and failure to perform daily duties. These symptoms could signal mental health problem for which a person needs professional help.

\section{Librarians and Mental Health}

Literature shows that when it comes to mental health in academic institutions, the focus has mostly been on faculty members and students who have experienced mental illness; yet, researches that have focuses specifically on librarians and their professional environments, including teaching and service provision to students are scarce (Burns \& Green, 2019).

Thompsom (2009) on the other hand, in an article on mental illness in the library workplace noted that mental health symptoms are hard to recognise or understand at the workplace for after all, librarians are not therapists. However, in times when stresses are increasing due to economic, professional or personal challenges; most people including librarians are susceptible to move into compromised state of mind. Emotions such as frustrations, anger or confusion may disrupt the workplace as a result of irrational behaviours and lack of coping mechanisms for life's challenges resulting in complaints and problems.

Additionally, Niebauer (2020) explored mental illness among librarians and found out that its prevalent as being a librarian is an 'emotional labour' for libraries are refuges for the stressed community members, the homeless and the mental ill and disabled and the librarian has to serve this diversified community of clients within an Institution with a friendly face all the time. This in turn can take a toll on the librarian's own mental health resulting into burnout, stress, weight loss and poor mental health.

In Tanzania, as in many other developing countries, concerns about low economic growth rates and low productivity persist. Also, regarding human capital development and well-being, health is oftentimes taken for granted by employees and policy-makers (Mbelle, 2005). Jenkins, Mbatia, Singleton and White (2010) observed that in Tanzania, the government has established key national policy frameworks and has recognised the links between poverty and physical illhealth; however, the role of mental health had not been explicitly considered. Yet, in 1990 the World Bank estimated that neuropsychiatric disorders formed 10.5 percent of global burden of disease and suggested that this could rise to 15 percent in 2020. In fact, the number has exceeded projected 15 percent and is now at 19 percent (Jenkins et al., 2010).

In developing countries, mental health problems are on the rise and Tanzania is not an exception. Despite the continual rise of mental health challenges in the country, as literature shows, awareness among employees and employers of mental health disorders and how they affect workers and result in low job performance remains rather low (Jenkins et al., 2010; Kaaya, 2014; Aladina, Pattinson \& Yusuf, 2016; Gberie, 2016; Ambikile \& Iseselo, 2017; Japhet, 2018). In consequence, there has been lack of organisational policies on assisting workers with mental health and unavailability of counselling services at the workplace to assist workers cope with 
mental health challenges, which arise due to socio-economic challenges facing workers, which include, but not limited to, financial challenges, stress, death of a loved one, traumatic experiences, abuse of alcohol or of recreational drugs, and unhealthy relationships. Thus, this study aims to look at the problem in detail using the IFM Library staff experience to understand their level of awareness and offer recommendations.

\section{Statement of the Problem}

Mental health among librarians is a bigger issue that research hasn't covered enough thus far (Niebauer, 2020; Thompson, 2009) and stigma surrounding mental health challenges affects academic librarians specifically regarding disclosure and unawareness of how to deal with their own stress related issues let alone those of the diversified clients that they serve on day-to-day basis (Burns \& Green, 2019).

In Africa, few studies have covered managing stress among librarians and information professionals in higher learning institutions despite the fact that many have complained of economic hardship, family problems and failure to cope with life's everyday challenges such as death, accidents, sickness and the like resulting in low job performance (Nawe, 1995; Bender \& Kennedy, 2004; Ilo, 2016). Additionally, no study has been conducted in the context of Tanzania librarians' work environment to explore mental health challenges whose symptoms manifests and hides in the same challenges that face workers every day at work and at home and its implications on job performance. This study therefore, aimed to cover that knowledge gap using the Institute of Finance Management Library staff experience to address the following objectives:

\section{Research Objectives}

1. To determine the level of awareness on mental health challenges among Library staff at the IFM Library.

2. To understand the implications of mental health challenges on job performance of Library staff at the IFM Library

\section{Methodology}

The study was conducted at the Institute of Finance Management (IFM) Library in Tanzania. Using the experience of library staff to understand their awareness of mental health challenges and its implication for their individual job performance. The study area was chosen so as to facilitate an in-depth understanding of the problem in a particularised context i.e. IFM library. This in turn ensured that the problem was explored in real-life context generating a more focused understanding of mental health challenges at the IFM library to assist in policy formulation, knowledge building and identification of future studies and population to be explored.

The study employed a pragmatic qualitative research design to explore the level of awareness of library staff on mental health challenges. The design was chosen due to its ability to focus on an individual person within an actual real-world situation. Salkind (2010) elaborates more on the richness of the design and notes that a pragmatic qualitative study identifies a

Awareness of Mental Health Challenges and its Implications for Job Performance among Library Staff at the Workplace: A Qualitative Study

Valeria Kyumana 
problem and views it within its broadest context; additionally, it allows for the formulation of research questions/inquiries which seeks to better understand and, ultimately, offer solution to the problem. Also, the research findings obtained could result in policy suggestions, new environmental initiatives, and social change.

Furthermore, when exploring health issues, qualitative methods are appropriate as they explore the complexities of social, economic, political and environmental factors that affect health and well-being. Also, it provides room for less manipulation of difficult research questions or variables to obtain a pre-determined answer, hence allowing for creating an authentic and deeper understanding of an individual experience of health and illness in the context of an individual or an organisation and its culture (Smith, Bekker \& Cheater, 2011).

The study involved library staff at the IFM library. Purposive sampling was used to select respondents for the study. Focus Group Discussions (FGDs) were used to collect data from library staff while interviews were conducted with two (2) heads of departments, and the head of library. Therefore, four (4) FGDs were held. Each discussion group comprised five (5) participants, hence a total of 20 participants. Five (5) interviews were held both face-to-face and via the telephone with the director, head of departments and heads of branch libraries in Mwanza and Dodoma Campus libraries.

Data obtained was subjected to relational content analysis and presented thematically. Written responses were recorded in a note-book as none of the respondents were comfortable with being recorded. Key themes emerging from the discussions and interviews were used for discussions. Ethical considerations were adhered to and no respondent's name was mentioned. Moreover, data obtained in confidence required permission from individual respondents before its presentation in the resultant report.

\section{Findings and Discussion}

\section{Awareness of mental health disorders}

Findings from the study indicate that most of the library staff were not aware of mental health challenges, namely anxiety, depression, post-traumatic stress disorder or schizophrenia. However when they were asked to indicate whether they had ever experienced reduced ability to concentrate due to worries or family problems or death of a loved one; if they had ever withdrawn from friends and activities due to debilitating sadness; or if they had ever felt overwhelmed with daily problems and stress to the point of having headaches, panic attacks or extreme fear of the outcome; or if they had ever indulged in alcohol (above their usual consumption) as the way to escape their problems to the point of debt; or if they had ever felt excessive anger or violence due to frustrations at work or with family members- many of the respondents were affirmative. In fact, most of the staff said they had felt one or more of these emotions at one point in their lives yet they did not know they had anything to do with mental health challenges and, indeed, they affected their job performance as many slacked, felt no morale to work whereas others chose to be absent and stay at home. During FGDs one of the library staff said: 
...I had felt so sad at one point in my life that I felt like I was going to be swallowed whole by feelings of apathy, self-loathing and failure. I don't know what I did to come out of the situation but my husband and family played a huge role in consoling me. However, I have seen a person I know drawn in self-flagellation because of divorce that I felt sorry for them. Overnight, their appearance became rough with un-ironed clothes and poor selfgrooming; they had debts everywhere and majority started avoiding lending money to the person which was mainly used for drinking to forget their sorrows. It was so surreal to watch a once well-established person lose complete control of one's life.

Another library staff during an FGD revealed their experience in dealing with grief which resulted in depression:

...when I lost my sister whom I was close to, most of my colleagues supported me financially and emotionally. Yet, three weeks after I reported for work I felt numb and empty. I was so sad most of the time and angry. What saddened me the most was the fact that my co-workers went on with lives happily, fulfilling their duties with cheer while I was breaking apart inside with grief. I couldn't talk to any one yet I longed to have a supportive hand at work. I wanted to stay home and not come to work...I wished for that. And every morning waking up was a struggle.

The World Health Organisation (2019) ranks depression to have higher burden than other psychiatric conditions such as Bipolar disorders and schizophrenia. Depression erodes an individual's ability to function at home, at work and socially. WHO further notes that depression affects individuals' relationships with family, friends and colleagues, while time off work or reduced productivity at work affects the financial situation of the organisation or push individuals into debt. The report also notes that in 2010 depression cost the European Union 92 billion Euros of which 54 billion were indirect costs related to absence from work. Additionally, some of the library staff noted that they experienced anxiety while at the same time fearing what could befall them tomorrow. During an FGD, one of the staff noted:

...life has become so difficult. At times, you wake up with no money at all and wonder how you are going to feed your family on a given day let alone manage to work for 10 hours. Things are not made better at the office as promotions fate are yet to be determined for many of us and debts are looming over us making life so stressful at times. This does not mean we are not grateful for our jobs but at times we wish more could be done to help staff as this will alleviate their preoccupation with their personal problems and focus on work.

Despite the fact that Herzberg's duel factor theory noted that money does not motivate workers; rather, its factors such as achievement, recognition, the work itself, responsibility, advancement and growth that will motivate (Herzberg, 1966) many library staff's economic problems stemmed from financial insecurity and lack of adequate income to sustain their lives at times. Sule, Amuni, Obasan and Banjo (2015) found that wages and salaries had not been given the importance they deserved in many organisations, yet they affect morale and the performance of

Awareness of Mental Health Challenges and its Implications for Job Performance among Library Staff at the Workplace: A Qualitative Study

Valeria Kyumana 
workers in a work environment. Additionally, Evans, Holker and Murray (2017) noted that financial difficulty is a common cause of mental health problems as 1 -in-4 people with mental health problems is also in debt and people feel guilty, ashamed and frustrated by financial difficulties, which compounds mental health problems as many people worry about how to make ends meet and have difficult relationships because of lacking money.

In Africa generally and Tanzania particularly, workers contend with a lot of challenges but at the top of the list is the financial crisis as the financial sector has come to a near standstill, hence leading to food crisis as workers spend over half of their income on basic foodstuff, which had been hit by a huge inflation recently (Grumiau \& Bakvis, 2009).

\section{Mental Health and Its Implications for Job Performance}

In a workplace, it was hard to establish whether a worker had a mental health challenge or simply being difficulty and refusing to work as a result. However, WHO's (2005) report on mental health policies and programmes at the workplace note that mental health challenges have a direct bearing on workplaces because of increased absenteeism, reduced productivity, and increased costs. Moreover, there is increasing evidence that both the content and the context of work can play a role in the development of mental health problems at the workplace (WHO, 2005). In an interview with the top senior Librarian the following statement emerged:

...everyone has problems yet some staff are very stubborn and lazy. They don't like to work and everyday they have one excuse after another on why they can't make it to work. We have had workers who are good yet turn around as time progresses and start to misbehave. We, as leaders, are not psychology expects, so we can't tell whether one's changed behaviour is a result of mental health challenge or they are just being difficult and refusing to work. We reinforce work regardless, for if we accommodate everyone excuses, no work will be done and no worker is ever fully satisfied with salary or the work environment and problems never end.

Bender and Kennedy (2004) contend that the economic implication of mental health for the workplace has been the subject of increasing publications in psychiatric literature; yet mental health and stress-related disability are vague and imprecise, complex and debatable issues in the context of the workplace. After all, many mental health disorders do not fit a simple cause-andeffect model. Additionally, a knowledge gap exists between mental health professionals and employers regarding symptom-based models of illness and responsibility-based models of work performance. However, Chopra (2009) assert that, this knowledge gap challenge notwithstanding, mental health disorders are associated with reduced workplace productivity and this impact is significant in developing countries where there is a paucity of research focusing on the relationship between mental health challenges and job performance.

On the other hand, Schott (1999) acknowledges that though knowledge of mental health has significantly increased over the years, the managers' understanding of the pervasiveness, treatment and impact on organisational life and productivity at workplaces has lagged behind. Chopra (2009) further notes that workplace factors may increase chances of mental illness if the environment is not conducive for workers. These factors include political environment, policies 
governing labour market, access to basic services such as health services and stability of social and family networks/relationships without forgetting fairness of workplace processes to include workplace procedures. Thus far, when looking at workplace conditions, attention has been put on impact of harsh working environments on people's human rights rather than their emotional wellbeing specifically (Chopra, 2009). In this study, a member of staff who is part of the library during FGDs said:

...feelings of resentment and hopelessness arise when we ought to do special duties especially during examinations when we are required to do duties beyond our normal working hours. We work hard and don't complain yet when it comes to payment we receive less than others who were doing the same work. We have tried to raise this issue but it has not been handled at all. We are told to be grateful with the little that we get. This situation is unfair and it pains us and hurts us more than you can imagine. It makes us lose morale to work but mostly it makes us feel inadequate.

Additionally, it is generally hard to diagnose mental health challenges amongst workers, yet their implications can be catastrophic to other co-workers if not addressed and the situation persists. Indeed, mental health challenges of one worker can negatively impact teamwork and cooperation, lead to heavier workloads for co-workers, distract good and hard-working co-workers, hence leading to laziness and mob psychology, low morale, increased workplace errors, accidents and injuries. Thus, it is imperative to intervene early and find ways to create positive and supportive work environments when problems arise. In this regard, one library staff said during FGDs:

... some people have one excuse after another on daily basis which, as workers, we are not privy to except the heads of department. They don't work much and when we see they get away with it without being punished, it lowers morale to give one hundred percent to the job. Instead the good workers start slacking too, making excuses and coming to work late. It really dampens the mood to work when you are the only one in the section carrying the entire heavy load.

Another Library assistant during FGDs noted that:

...the library profession is considered a low status cadre in many higher learning institutions consisting of simple duties like organizing books on the shelf only. This has led to many academic and other staff -looking down on library staff. At times, when we have meetings with management, you could feel they are not sure if your opinion will gravitate towards anything substantial other than demanding books to fill the library. This has resulted into inferiority complex, stress and anxiety whenever one wants to say something but fear backlash due to that mentality many have of the library profession and professionals.

Kyumana (2018) while investigating job satisfaction among library staff in selected higher learning institutions found out that majority of the library staff were dissatisfied with their social

Awareness of Mental Health Challenges and its Implications for Job Performance among Library Staff at the Workplace: A Qualitative Study

Valeria Kyumana 
status in the studied libraries. While Nawe (1995) found similar sentiments where by respondents disclosed that the library profession has low status in both Botswana and Tanzania due to lack of awareness of what constitutes librarianship. Yet there was no study that linked low status to result into mental health challenges but saw low status of the profession as an impediment to job performance, job satisfaction and confidence at work.

Regarding the difficulty in identifying mental health challenges, one staff during FGDs, shared an experience with difficulty diagnosis thusly:

...I once had a cousin who came to visit me from a rural area seeking medical attention at the Muhimbili National Hospital [in Dar es Salaam]. He was complaining of chest pains, shortness of breath and lack of sleep. In fact, he was afraid of sleeping as he said he heard voices and saw people coming to get him in his dreams wearing red clothes and forcing him into a grave. At the hospital, the doctors told us there was no problem with his heart but he has panic attacks, stress and early onset schizophrenia. He didn't believe this diagnosis; in fact, he left immediately to go and see a traditional healer as he deeply believed that he was bewitched and people from his workplace were out to get him since his relationship with his boss was exceptionally good and his side business was booming.

Quintanilla (2010) notes that, historically, in the Middle Ages some diseases, especially mental health disorders were not associated with natural causes but rather with supernatural forces or malignant spirits, especially when physicians were unable to diagnose or deal with it. In Tanzania, Barnett (2012) explicates that for centuries witchcraft has explained anything inexplicable occurring among people in rural villages such as a severely sick child or a strange illness. With little awareness or no education, many people are more likely to succumb to the claims of traditional healers and pass down those beliefs to the next generation.

On the other hand, disclosing mental health challenges among workers or anyone in the society is still a taboo. Many people fear discrimination and the social stigma attached to admitting that one is struggling with depression, anxiety, or post-traumatic stress disorder. During interview, one of the staff said:

...I have been struggling with disorganised thoughts and behaviour for most of my life. Some moments I am okay; and in some instances I'm not. I was diagnosed with psychosis and I manage it with medication from time to time. Yet, I am fine, smart and intelligent and I work hard. Nobody knows; yet they are always baffled by my abrupt changes in behaviour. I don't want to tell them of my diagnosis for fear of being stigmatised although I suspect most of them know.

According to Hampson, Watt and Hicks (2020), psychosis is a mental health condition identified by symptoms such as delusions, hallucinations, disorganised thinking and disorganised behaviour. McKinley (2019) agrees that identification of mental health challenges is difficult and due to stigma, many people fail to open up and seek help. As for an employer, knowing how to identify and support employees who are struggling with mental health can be imperative for their overall performance and work. Besides, identifying employees who are struggling with mental 
health issues cannot be straightforward. Signs that a worker might be facing mental health difficulties at work include mood swings or noticeable changes in behaviour, lack of clarity or focus at work, coming across as nervous or preoccupied at work and lack of interest in engaging with colleagues, increasing in normal drinking or smoking habits, drastic change in weight or appearance, and absenteeism or missed periods of work.

Additionally, transparency amongst workers about mental health struggles still poses a challenge. Pinfold and Huxley (2003) agrees that indeed there is still a huge challenge facing society regarding social stigma and discrimination associated with mental health challenges and cultural and negative deep-rooted beliefs persists. On top of that, Kohnert (1996) agrees that belief in occult forces is still deeply rooted in many African societies despite the level of education, religion and social class of the people and most often witchcraft accusations and beliefs sometimes may be an indicator of hidden social conflicts difficult to detect by other methods. Though there are programmes around the world to reduce psychiatric stigma; Alidina et al., (2016) observed that in Tanzania, mental health services were scarce and that most communities and the country generally lacked the capability to support those living with mental and emotional distress.

\section{Conclusions and Recommendations}

Workers spend a lot of time at work interacting with their co-workers and supervisors. This is also true of library staff, who were the subject of this study. However, performance problems are notably caused by personal issues employees face, which in turn result in performance decline and, eventually, affect organisational performance. But critical questions remain: How do we know when mental health symptoms and challenges in an individual employee are out of hand and when one requires professional help? After all, without getting necessary help they could sink deeper into the abyss. Since everyone faces problems and experiences some of these symptoms at one point in life, when is it appropriate to intervene? It is also critical for an organisation/institution to recognise that neglecting mental health amongst workers culminates into difficulties in achieving organisational goals and vision while investing in mental health means promoting resilience amongst workers. In short, mental health is a means to socio-

Awareness of Mental Health Challenges and its Implications for Job Performance among Library Staff at the Workplace: A Qualitative Study

Valeria Kyumana 
economic development, hence a worthy goal to pursue both on an individual and institutional capacity.

Findings of the study indicate that most of the library staff have low awareness of mental health challenges though when symptoms were enumerated to them, most agreed that they had experienced them at some point in their lives or have seen someone in their lives struggling, eventually affecting his or her personal and professional life. Moreover, it was noted that mental health challenges arise due to eventualities in life bringing new challenges and unpredictable events in a worker's life. These challenges include financial challenges, disputes among couples, conflicts with co-workers and neighbours and traumas such as death, loss or a depressive episode. All these challenges take a toll on the mental health of an employee and awareness is imperative to discern when the impact is extreme and when external professional help is necessary to manage the event. Failure to cope with these challenges could result in loss of productivity, absenteeism, substance abuse and suicidal thoughts.

Thus based on the study findings, education need to be provided to library staff and other employees of the Institute pertaining to different types of mental health challenges, their symptoms, and how to manage them so that one can seek help before extreme forms of these challenges manifest, for instance, violence, suicidal thoughts and eventual admittance to a psychiatric hospital. Also, research can be conducted to include other staff at the Institute and other higher learning institutions in Tanzania (faculty staff members and administrative staff) to examine their awareness regarding mental health challenges so that education and policies provided and formulated respectively can be inclusive and not tailored to library staff only. This in turn will result into healthy minds at the workplace leading to high job performance and productivity.

Additionally, most of the workers recommended the employment of an Institution counsellor to help workers deal with life challenges by identifying troubling behaviours and counselling them accordingly, hence improving work performance and productivity. In life, each person varyingly experiences the hard blunt of life's struggle that can tilt their axis and shake their world. In these instances, most people need a reminder that all would be well or a helping hand to see them survive the trauma, struggles or problem facing them. In this regard, Glenn Close during the 2018 mental health awareness month noted: “...what mental health needs is more sunlight, more candour, and more unashamed conversation" to inspire overcoming obstacles, seeking help and stopping shame and stigma surrounding mental health struggles.

In Tanzania, mental health policies are in place including the 2003 mental health guidelines, a key component of the National Health Policy. In 2008, an amendment of the Mental Health Act incorporated and underscored access to quality services and the rights of the mentally-ill. Yet, institutional/organisational policies have yet to be established. Thus, this paper recommends the formulating of such a policy at the organizational level to facilitate a deeper understanding of mental health challenges and how to best help workers to enhance job 
performance while creating a healthy environment for workers to have safe dialogues without recourse to fear, shame, stigma and discrimination, often associated with mental health.

\section{References}

Alidina, Z., Pattinson, M. \& Yusuf, F. (2016). From well-meaning to well-being: bridging the gap in mental health awareness in Tanzania. Annals of Global Health, 82(3), 397-436.

Ambikile, J. S. \& Iseselo, M. K. (2017). Mental health care and delivery system at Temeke hospital in Dar es Salaam, Tanzania. BMC Psychiatry, 17(1), 1-13.

Aultman, J.M. (2016). Psychiatric diagnostic uncertainty: Challenges to patient-centred care. AMA Journal of Ethics, 18(6), 579-586.

Barnett, E. (2012). Witchcraft in Tanzania: the good, the bad and the persecution. Retrieved from https://edition.cnn.com/2012/10/05/world/africa/tanzania-witchcraft.html

Bender, A. \& Kennedy, S. (2004). Mental health and mental illness in the workplace: diagnostic and treatment issues. HealthCare Papers, 5(2), 54-67.

Bever, E. (2000). Witchcraft fears and psychological factors in disease. The Journal of Interdisciplinary History, 30(4), 573-590.

Burns, E. \& Green, K. E. C. (2019). Academic librarians' experiences and perceptions on mental illness stigma and the workplace. College \& Research Libraries, 80(5), 638-657.

Bywaters, J. (2005). Public mental health in England since 1997: past, present and future. Journal of Public Mental Health, 4(1), 13-19.

Chopra, P. (2009). Mental health and the workplace: issues for developing countries. International Journal of Mental Health Systems, 3(1), 1-9.

Corlett, S. (2012). Policy watch: implementing the mental health strategy. Mental Health and Social inclusion, 16(4), 164-168.

Erinosho, O. A. (1977). Belief-system and the concept of mental illness among medical students in developing country: A Nigerian example. Journal of Anthropological Research, 33(2), 158-166.

Evans, K., Holkar, M. \& Murray, N. (2017). Overstretched, overdrawn \& underserved: financial difficulty and mental health at work. Mental Health and Money Policy Institute.

Gberie, L. (2016). Mental illness: invisible but devastating. Retrieved from https://www.un.org/africarenewal/magazine/december-2016-march-2017/mental-illnessinvisible-devastating

Hampson, M.E., Watt, B.D. \& Hicks, R. E. (2020). Impacts of stigma and discrimination in the workplace on people living with psychosis. BMC Psychiatry, 20(1), 1-11.

Herzberg, F. (1966). Work and nature of man. World Publishing.

Huxley, P. (2009). The contribution of social science to mental health services research and development: a SWOT Analysis. Journal of Mental Health, 10(2), 117-120.

Hsieh, H. \& Shannon, S. E. (2005). Three approaches to qualitative content analysis. Qualitative Health Research, 5(9), 1277-1288.

Ilo, P. (2016). Managing stress among librarians in selected university libraries in Ogun State Nigeria. Library Philosophy and Practice (e-journal). 1343. DOI: https://digitalcommons.unl.edu/libphilprac/1343

Awareness of Mental Health Challenges and its Implications for Job Performance among Library Staff at the Workplace: A Qualitative Study

Valeria Kyumana 
Japhet B. (2018). Do only 1\% of Tanzanians suffer from mental illness? how many Tanzanians have sought treatment for mental illness? Retrieved from https://pesacheck.org/do-only1-of-tanzanians-suffer-from-mental-illness-6772a71ac47d

Jenkins, R., Mbatia, J., Singleton, N. \& White, B. (2010). Common mental disorders and risk factors in urban Tanzania. International Journal of Environmental Research and Public Health, 7(6), 2543-2558.

Kaaya, S. (2014). Mental health service systems in Tanzania. Retrieved from https://www.ntnu.no/documents/1323615/122107118/KAAYA,Mental+health+in+Tanza nia2014-KAAYA.pdf/42a5997a-2d5e-4747-8285-d3e89d3027c/

Kamin, T. (2006). Mental health promotion: a perspective from Slovenia. Journal of Public Mental Health, 5(1), 24-28.

Kohnert, D. (1996). Magic and witchcraft: Implications for democratization and povertyalleviating aid in Africa. World Development, 24(8), 1347-1355.

Kyumana, V. (2018). An investigation of job satisfaction among library staff in selected academic libraries in Tanzania. PhD Thesis. University of Dar es Salaam, Tanzania.

Lanese, N. (2019). What is mental health? Retrieved from https://www.livescience.com/mentalhealth.html

Lund, C. (2018). Why Africa needs to start focusing on the neglected issue of mental health. The Conversation Africa, Inc. Retrieved from https://theconversation.com/why-africa-needsto-start-focusing-on-the-neglected-issue-of-mental-health-91406

Mbelle, A.V.Y. (2005). Productivity performance in developing countries. Country case studies: Tanzania. Productivity performance in developing countries research programme, trends and policies. United National Industrial Development Organization.

McKinley, M. (2019). Identifying employees suffering from mental health issues. Retrieved from https://www.morganmckinley.com/ie/article/identifying-employees-suffering-mentalhealth-issues

Nawe, J. (1995). Human resource issues and problems for library and information Services with Reference to Southern African development community member countries. PhD Thesis, University of Wales, Wales.

Nawe, J. (1995). Work-related stress among the library and information workforce. Library Review, 44(6), 30-37.

Niebauer, A. (2020). Information studies prof works to address mental illness among librarians. Retrieved from https://uwm.edu/news/information-studies-prof-works-to-address-mentalillness-among-librarians/

Newson, J. J. (2018). The challenges of mental health diagnosis. Retrieved from https://saplenlabs.org/the-challenges-of-mental-health-diagnosis/

Pinfold, V., Toulmin, H., Thomicroft, G., Huxley, P., Farmer, P. \& Graham, T. (2003). Reducing psychiatric stigma and discrimination: evaluation of educational interventions in UK secondary schools. The British Journal of Psychiatry, 182(2), 342-346.

Quintanilla, B. (2010). Witchcraft or mental illness? Retrieved from https://www.psychiatrictimes.com/view/witchcraft-or-mental-illness

Riekert, S. (2009). A new earth: awakening your life's purpose, Eckhart, Tolle: book review. New Voices in Psychology, 5(2), 102-104.

Rothfuss, P. (2007). The name of the wind. Penguin Group DAW. 
Salkind, N. J. (2010). Encyclopaedia of research design. SAGE Publications, Inc. DOI: $10.4135 / 9781412961288$.

Sankoh, O., Sevalie, S. \& Weston, M. (2018). Mental health in Africa. The Lancet Global Health, 6(9), 954- 955.

Schott, R. L. (1999). Managers and mental health: Mental illness and the workplace. Public Personnel Management, 28(2), 161-183.

Smith, J., Bekker, H. \& Cheater, F. (2011). Theoretical versus pragmatic design in qualitative research. Nurse Researcher, 18(2), 39-51.

Sule, O. E., Amuni, S. I., Obasani, K. A. \& Banjo, H. A. (2015). Wages and salary as a motivational tool for enhancing organizational performance: a survey of selected Nigerian workplace. EuroEconomica, 34(1), 6-26.

Thompson, C. (2009). Mental illness in the library workplace. Retrieved from https://alaapa.org/newsletter/2009.07/13/mental-illness-in-the-library-workplace/

World health Organization (2005). Mental health policies and programmes in the workplace. WHO Press.

World Health Organisation. (2019). Mental health. Retrieved from https://www.who.int/news$\mathrm{room} /$ facts-in-pictures/detail/mental-health

Zhang, S. (2019). What needs to be said about mental health in medicine. Retrieved from https://scopeblog.stanford.edu/2019/04/17/what-needs-to-be-said-about-mental-health-inmedicine/

Awareness of Mental Health Challenges and its Implications for Job Performance among Library Staff at the Workplace: A Qualitative Study

Valeria Kyumana 